\title{
Prevalence of microalbuminuria and diagnostic value of dipstick proteinuria in outpatients from HIV clinics in Bukavu, the Democratic Republic of Congo
}

\author{
Mannix Imani Masimango ${ }^{1,2,6^{*}}$, Ernest Kiswaya Sumailii, Michel Jadoul ${ }^{3}$, Pierre Wallemacq ${ }^{4}$, \\ Dieudonné Kanigula Mubagwa ${ }^{5}$, Rissassy Jean-Robert Makulo' ${ }^{1}$ François Bompeka Lepira ${ }^{1}$ \\ and Nazaire Mangani Nseka ${ }^{1}$
}

\begin{abstract}
Background: Microalbuminuria is a marker of early kidney disease and high cardiovascular risk in various populations, including HIV positive patients. However, the diagnostic value of qualitative (dipstick) proteinuria and the burden of microalbuminuria in HIV positive patients living in sub-Saharan Africa are relatively unclear.

Methods: In a cross-sectional study, 235 HIV-positive outpatients were screened for proteinuria in 3 HIV-clinics in Bukavu. A spot urine sample from each subject was tested both by a dipstick and albumin-creatinine-ratio (ACR) assay. The performance of dipstick proteinuria exceeding $1+$ was compared with that of microalbuminuria ( $\geq 30 \mathrm{mg} / \mathrm{g}$ creatinine).

Results: The prevalence of microalbuminuria and dipstick proteinuria $\geq(1+), \geq(2+)$ and $\geq(3+)$ was $11 \%, 41 \%, 3.5 \%$ and $0.7 \%$, respectively.

Compared to microalbuminuria, the dipstick (proteinuria of $1+$ or greater) had an overall sensitivity of $60 \%$ and a specificity of $61 \%$. The positive predictive value was $15.4 \%$ and the negative predictive value $92.8 \%$.
\end{abstract}

Conclusion: Proteinuria is highly prevalent in HIV positive patients. The limited sensitivity and specificity of the dipstick to detect significant microalbuminuria make it unattractive as a screening tool in HIV positive patients.

Keywords: Dipstick proteinuria, Albumin/creatinine ratio, Diagnostic value, HIV-patients

\section{Background}

The prevalence of chronic kidney disease (CKD) is high in the African HIV infected population [1,2] where late referral to hospital and scarce possibilities of renal replacement therapy are well known. The early detection of CKD would provide the opportunity to implement strategies known to slow CKD progression [3,4]. Thus, the identification of overt proteinuria or even microalbuminuria, might be an important tool for the early detection of CKD in HIV-infected individuals [5,6]. The

\footnotetext{
* Correspondence: masimax2003@yahoo.fr

'Department of Medicine, Université Catholique de Bukavu, Bukavu, DR Congo

${ }^{2}$ Nephrology Unit, Department of Medicine, Université de Kinshasa, Kinshasa, DR Congo

Full list of author information is available at the end of the article
}

Infectious Diseases Society of America (IDSA) guidelines on the management of chronic kidney disease in HIVpositive patients recommend the use of a urine dipstick, with a threshold for detection of renal disease at $1+$ proteinuria. When dipstick is $\geq 1$, a quantification of proteinuria is recommended. Currently, this relies on the albumin/ creatinine ratio (ACR) measured on a spot of urine $[7,8]$. However, in many emerging countries, the dipstick remains the only method used for the evaluation of proteinuria. Nevertheless, it is recognized that dipsticks may have poor sensitivity in detecting low-grade proteinuria [9].

The purpose of the current study was to evaluate the prevalence of proteinuria in HIV-positive patients and to assess the diagnostic value of urinary dipstick as screening test for proteinuria compared with the albumin/creatinine ratio $(\mathrm{ACR})$. 


\section{Methods}

Written informed consent for participation in the study was obtained from participants.

A cross-sectional survey was conducted in March and April 2012 in 3 outpatient HIV-clinics in Bukavu, the main town in the eastern rural part of the Democratic Republic of Congo (DRC).

Two hundred and sixty consecutive HIV-1 positive adults ( $\geq 18$ years) who routinely attended one of the clinics during the survey period were screened.

Single spot urine specimens were collected in the morning. Urine samples containing blood (1+ or greater), white blood cells $(1+$ or greater) and/ or nitrites were excluded. This left 235 subjects in whom, both a urine dipstick test and a urine albumin to creatinine ratio measurement were performed (ACR). The results of urine dipstick (Multistix 8 $\mathrm{SG}^{\circledast}$, Siemens Healthcare Diagnostics, France) were read as either negative $(<30 \mathrm{mg} / \mathrm{dl})$ or positive at $1+, 2+, 3+$ or greater, corresponding approximately to protein concentrations of $30,100 \mathrm{mg} / \mathrm{dl}, 300$ and $\geq 2000 \mathrm{mg} / \mathrm{dl}$. ACR was performed using the DCA Vantage ${ }^{\mathrm{TM}}$ analyzer (Siemens Healthcare Diagnostics Pyt Ltd., 885 Mountain Highway, Australia), utilizing an immunoassay method for Albumin. Microalbuminuria was defined by a urinary albumin-tocreatinine ratio (ACR) 30-299 mg/g and macroalbuminuria by an ACR $>300 \mathrm{mg} / \mathrm{g}$. The diagnostic value (sensitivity, specificity, positive predictive value, negative predictive value) of dipstick $\geq 1+$ and $\geq 2+$ to detect micro or macro albuminuria was thus assessed.

\section{Statistical tools}

The processing and data analysis were performed using SPPS software Windows version 18.0 and MedCalc 9.2.1.0.

Quantitative albuminuria expressed as ACR was subdivided into three sub-groups: $<30 \mathrm{mg} / \mathrm{g}$ (normoalbuminuria), 30 to $299 \mathrm{mg} / \mathrm{g}$ (microalbuminuria) and $\geq 300 \mathrm{mg} / \mathrm{g}$ (macroalbuminuria), and compared with the respective results of the dipstick on the same sample.

The diagnostic value (sensitivity, specificity, positive predictive value, negative predictive value) of the dipstick $1+$ or greater $(>30 \mathrm{mg} / \mathrm{dl}$ ) was thus studied. The cutoff of $1+$ was chosen on the basis of IDSA's recommendations.

\section{Ethical issues}

Permission obtained from the Ethics Committee of the school of Medicine of the Catholic University of Bukavu (Commission Institutionnelle d'Ethique, 09 juin 2012).

\section{Results}

A total of 260 patients were contacted. Twenty-five had to be excluded because of hematuria $(n=12)$, detection of nitrites in urine $(n=8)$ or leucocyturia $(n=5)$. The 25 excluded patients had demographic characteristics similar to those of the 235 included patients.

A total of 235 patients were thus included, of whom 179 (76.2\%) were on antiretroviral therapy. Baseline data are provided in Tables 1, 2 and 3. All patients were African. Median age was 40 years (IQR 18-74) and $73.2 \%$ were women.

Median CD4 cell count was 480 cells /mm3 (IQR 101202). The overall prevalence of proteinuria according to ACR was $10.6 \%$ (95\% CI 6.67- 14.53), 8.9\% for microalbuminuria (ACR $30-300 \mathrm{mg} / \mathrm{g}$ ) and $1.7 \%$ for macroalbuminuria (ACR $>300 \mathrm{mg} / \mathrm{g}$ ). In contrast, the prevalence of dipstick urine protein $(1+),(2+)$ and $(3+)$ were $37 \%$, $3.4 \%$ and $0.9 \%$, respectively.

Regarding the intensity of proteinuria, no difference was observed between the groups receiving antiretroviral versus ART naive patients.

The 235 paired dipstick and quantitative results are displayed in Table 4.

Seventy-six (36.2\%) of 210 patients with urine ACR < $30 \mathrm{mg} / \mathrm{g}$ had a positive urine dipstick results (falsepositive result $\geq 1+$ ). Furthermore, $10(47.6 \%)$ of 21 patients with abnormal low-level albuminuria (UACR 30 to $299 \mathrm{mg} / \mathrm{g}$ ) had negative urine dipstick results (falsenegative result: $1+$ ).

In comparison with $\mathrm{ACR}>30 \mathrm{mg} / \mathrm{g}$, urine dipstick had an overall sensitivity and specificity of $60 \%$ and $61 \%$, respectively. At a prevalence of proteinuria of $10.6 \%$, the positive predictive value of positive urine dipstick for ACR $>30 \mathrm{mg} / \mathrm{g}$ was $15.4 \%$ and the negative predictive value $92.8 \%$.

\section{Discussion}

The purposes of this study were to determine the prevalence of microalbuminuria in an HIV-infected clinic population in DRC and the performance of the dipstick urine test compared to the ACR. Approximately three quarter of the subjects were women, consistent with other data showing a feminization of HIV infection, particularly in Africa [10,11].

In the present study, the prevalence of proteinuria with dipstick test $(\geq 1+)$ was $41.3 \%$. Cohort studies suggest that approximately $30 \%$ of HIV-positive individuals have proteinuria $(\geq 1+)$. Similar results are reported by Fabian et al. in South Africa (44\%) [12] and Jao et al. in Cameroon (39\%) [13]. However, Struik et al. [14] and Longo et al. [15] reported a lower prevalence, 23 and $21 \%$ respectively. Furthermore, the prevalence of quantitative proteinuria defined as $\mathrm{ACR} \geq 30 \mathrm{mg} / \mathrm{g}$ was $10.6 \%$. This prevalence is similar to that of earlier reports varying from $6 \%$ to $30 \%$ in the HIVinfected, which is three to five times higher than in the general population [16-19]. Differences in methodological approach and in clinical profile of patients could probably explain the variability of results between studies. 
Table 1 General characteristics of studied population

\begin{tabular}{|c|c|c|c|c|}
\hline Variables & $\begin{array}{l}\text { Whole group } \\
n=235\end{array}$ & $\begin{array}{l}\text { HAART subjects } \\
n=179\end{array}$ & $\begin{array}{l}\text { ART naive subjects } \\
n=56\end{array}$ & $p$ \\
\hline Female, \% & $172(73,2)$ & $127(54)$ & $45(19,1)$ & 0,0001 \\
\hline Age (years, median) & $40,0 \pm 10,7$ & $42,3 \pm 10,6$ & $35 \pm 9,7$ & $<0,0001$ \\
\hline \multicolumn{5}{|l|}{ Family history of: } \\
\hline - DM & $48(20,4)$ & $41(17,4)$ & $7(3)$ & 0,06 \\
\hline - Hypertension & $72(30,6)$ & $54(23,0)$ & $18(7,7)$ & 0,28 \\
\hline - Obesity & $50(21,3)$ & $39(16,6)$ & $11(4,7)$ & 0,61 \\
\hline$-C K D$ & $22(9,4)$ & $15(6,4)$ & $7(3,0)$ & 0,49 \\
\hline \multicolumn{5}{|l|}{ Comorbidities } \\
\hline - DM & $4(1,7)$ & $4(1,7)$ & $0(0)$ & 0,597 \\
\hline - Hypertension & $110(46,8)$ & $87(37,0)$ & $23(9,8)$ & 0,02 \\
\hline Level of education $<6$ years & $113(48,9)$ & $79(34,2)$ & $34(14,7)$ & 0,05 \\
\hline \multicolumn{5}{|l|}{ Marital status: } \\
\hline - Married & $104(55,7)$ & $78(43)$ & $26(12,8)$ & 0,01 \\
\hline - widow & $131(55,7)$ & $101(43)$ & $30(12,8)$ & 0,005 \\
\hline History of smoking & $28(11,9)$ & $21(8,9)$ & 7 (3) & 0,73 \\
\hline History of alcohol consumption & $107(45,5)$ & $82(34,9)$ & $25(10,6)$ & 0,036 \\
\hline History of medicinal plants use & $29(12,3)$ & $19(8,1)$ & $10(4,3)$ & 0,69 \\
\hline History of NSAIDS use & $49(20,9)$ & $39(16,6)$ & $10(4,3)$ & 0,62 \\
\hline
\end{tabular}

Data are expressed as absolute or relative frequencies or mean plus the standard deviation (SD) as appropriate.

Table 2 Clinical characteristics of subjects

\begin{tabular}{|c|c|c|c|c|}
\hline Variables & $\begin{array}{c}\text { Whole group } \\
\qquad n=235\end{array}$ & $\begin{array}{l}\text { HAART subjects } \\
\qquad n=179\end{array}$ & $\begin{array}{l}\text { ART naive subjects } \\
\qquad \mathrm{n}=56\end{array}$ & p \\
\hline Known HIV infection duration (years) & $4,7 \pm 3,2$ & $5,3 \pm 3,04$ & $2,8 \pm 2,9$ & $<0,0001$ \\
\hline Duration of HAART (months) & NA & $46,2 \pm 30,08$ & NA & \\
\hline \multicolumn{5}{|l|}{ WHO stage for HIV clinical disease: } \\
\hline - Stage 1 & $25(10,6)$ & $12(5,1)$ & $13(5,5)$ & 0,39 \\
\hline - Stage 2 & $53(22,6)$ & $21(8,9)$ & $32(13,6)$ & 0,93 \\
\hline - Stage 3 & $140(59,6)$ & $129(54,9)$ & $11(4,7)$ & 0,0039 \\
\hline - Stage 4 & $17(7,2)$ & $17(7,2)$ & 0 & $<0,0001$ \\
\hline Body mass index $\left(\mathrm{kg} / \mathrm{m}^{2}\right)$ & $22,3 \pm 3,8$ & $22,5 \pm 3,9$ & $21,7 \pm 3,4$ & 0,198 \\
\hline $\mathrm{SBP}(\mathrm{mmHg})$ & $118,82 \pm 20,89$ & $120,58 \pm 21,7$ & $113,2 \pm 16,7$ & 0,023 \\
\hline $\mathrm{DBP}(\mathrm{mmHg})$ & $77,7 \pm 14,02$ & $79,8 \pm 14,7$ & $71,8 \pm 11,6$ & 0,0002 \\
\hline \multicolumn{5}{|l|}{ HAART regimen: } \\
\hline$A Z T+3 T C+N V P$ & NA & $164(94,8)$ & NA & \\
\hline$d 4 T+3 T C+N V P$ & NA & $3(1,6)$ & NA & \\
\hline$A B C+D D I+L p / r$ & NA & $9(5)$ & NA & \\
\hline $\mathrm{TDF}+3 \mathrm{TC}+\mathrm{EFV}$ & NA & $3(1,6)$ & NA & \\
\hline
\end{tabular}

$\mathrm{HTA}=$ hypertension; $\mathrm{BMC}=$ body mass index; $\mathrm{SBP}=$ Systolic blood pressure; $\mathrm{DBP}=$ diastolic blood pressure; $\mathrm{CKD}$ = chronic kidney disease; HAART: Highly active antiretroviral therapy. NA: not applicable; d4T: stavudine, 3TC: lamivudine, NVP: nevirapine, ABC: abacavir, DDI: didanosine, Lp/r : lopinavir/ritonavir, EFV: efavirenz, TDF: tenofovir. 
Table 3 Biological characteristics of subjects

\begin{tabular}{|c|c|c|c|c|}
\hline Variable & Whole group & HAART group & ART naïve group & $p$ \\
\hline Fasting glycaemia & $103,5 \pm 14,4$ & $104,2 \pm 15,1$ & $100,3 \pm 10,6$ & 0,27 \\
\hline Hemoglobin & $13,3 \pm 2,0$ & $13,5 \pm 1,9$ & $12,7 \pm 2,2$ & 0,01 \\
\hline HBs Ag positive & $5(1,9)$ & $5(2,1)$ & $0(0)$ & 0,44 \\
\hline Anti HCV positive & $3(1,2)$ & $1(0,4)$ & $2(0,9)$ & $<0,0001$ \\
\hline \multicolumn{5}{|c|}{ CD4 (cells $/ \mathrm{mm}^{3}$ increment): } \\
\hline$-<200$ & $22(10,7)$ & $14(6,8)$ & $8(3,9)$ & 0,50 \\
\hline$-200-499$ & $96(46,8)$ & $80(39)$ & $16(7,8)$ & 0,034 \\
\hline$->500$ & $87(42,4)$ & $66(32,2)$ & $21(10,2)$ & 0,089 \\
\hline
\end{tabular}

Variables are absolute numbers and relative frequencies or means plus the standard deviation (SD) as appropriate. CD4: cluster of differentiation.

Although, this study did not address the specific causes of proteinuria in individual subjects, it is likely that proteinuria is related to HIV itself. Experimental studies demonstrate a direct impact of viral components (gp120, TAT) on the endothelium, as they lead to the expression of adhesion molecules (intercellular adhesion molecule [ICAM], E-selectin), a prothrombotic state (increase of von Willebrand factor, plasminogen activator inhibitor-[PAI-]1, tissue plasminogen activator [t-PA], tissue factor). In addition, soluble adhesion molecules (selectin, ICAM) were found to be increased in HIV-infected persons [20]. HIV-associated nephropathy (HIVAN) is the commonest biopsy finding among patients with HIV infection who present with proteinuria. Han et al. reported that $25 \%$ of naïve HIV-positive black patients (without hypertension, diabetes and with serum creatinine $<250 \mu \mathrm{mol} / \mathrm{L}$ ), have microalbuminuria, and that HIVAN was found in $86 \%$ of the subset of such patients with persistent micro albuminuria [19].

The results of our study suggest that the urine dipstick may not be an adequate tool for screening for proteinuria in HIV-positive patients. As a screening test, the sensitivity $(60 \%)$ and specificity (61\%) of a single dipstick is poor. In fact, at lower levels of proteinuria (30 to $299 \mathrm{mg} / \mathrm{g}$ ), a threshold of $1+$ dipstick had a false-negative rate of $47.6 \%$. Therefore, nearly 1 in 2 patients with proteinuria in this range may not be recognized and may have delayed workup and treatment. In addition, the proportion of false positives was $36 \%$. Consequently, one to 3 patients

Table 4 Comparison between the dipstick and the ACR in 235 patients

\begin{tabular}{lcccc}
\hline \multicolumn{5}{c}{ A/C ratio $(\mathbf{m g} / \mathbf{g})$} \\
\hline Urine dipstick & $<30$ & $30-299$ & $\geq 300$ & Total \\
& $\mathrm{n}=210$ & $\mathrm{n}=21$ & $\mathrm{n}=4$ & $\mathrm{n}=235$ \\
0 & 128 & 10 & 0 & 138 \\
$1+$ & 76 & 10 & 1 & 87 \\
$\geq 2+$ & 6 & 1 & 3 & 10 \\
\hline
\end{tabular}

$\left(^{*}\right)$ The numbers with gray shading correspond to false-positive dipstick results. The numbers highlighted in orange are false-negative ones. with positive dipstick (1+) could be falsely considered to be at high cardiovascular and kidney risk.

Several studies reported the poor sensitivity of dipstick testing to identify early renal disease in HIV-population [9], hypertensive [21] and diabetic patients [22]. A recent study has demonstrated that the sensitivity of dipstick test, may be affected by urinary concentration [9]. In addition, dipstick tests may miss about one out of five people with kidney disease, and positive dipstick test results for proteinuria may have to be confirmed by other laboratory tests [23]. In fact, in a study of 166 HIVinfected persons who underwent both a urine dipstick and a spot urine protein-to-creatinine ratio within a 48hour period, $21 \%$ of those with low but overt proteinuria (300 to $900 \mathrm{mg} / \mathrm{g}$ creatinine) were not detected by urine dipstick. So, in individuals at renal risk, such as HIV + patients, the search for microalbuminuria is recommended when the dipstick is negative. Furthermore, the recent Kidney Disease Initiative and Global Outcome (KDIGO) CKD Guidelines recommend, in individuals with proteinuria by dipstick, to perform confirmatory protein quantification within 3 months [24]. Defining proteinuria as a positive urine dipstick test on two occasions [25] could have reduced the false positive rate in our study, but probably at the expense of an even higher false negative rate.

\section{Conclusion}

\section{Strengths of the study}

Because of the high prevalence of proteinuria, early screening efforts should be encouraged in HIV-patients both before and under antiretroviral treatment. Based on the accuracy of the semi-quantitative urine dipstick, the KDIGO CKD Guidelines suggest the use of either a spot protein-to-creatinine or spot albumin-to-creatinine ratio for kidney disease screening [24]. The results of the current study question the use of the urine dipstick as screening tool for low-level proteinuria in HIV patients. Although dipstick testing would decrease costs, it would fail to diagnose most patients with microalbuminuria, an early marker of glomerular injury. Therefore, HIV + 
patients with negative dipstick should be screened for microalbuminuria. The Infectious Diseases Society of America (IDSA) guidelines that recommend using the dipstick as a screening tool may need to be revisited and updated.

\section{Limitations of the study}

It is a cross-sectional study of consecutively recruited patients with a single measurement (serum creatinine and proteinuria) and a relatively small sample size, thus limiting the generalization of the results to the entire population of patients living with AIDS. In addition, patients naive to ART were also underrepresented limiting the generalization of results obtained.

\section{Competing interests}

The authors declare that they have no competing interests.

\section{Authors' contributions}

SK participated in the design of the study and performed the statistical analysis; MJ conceived the study and participated in its design and coordination; KM has been involved in revising critically the manuscript; PW has been involved in revising critically the manuscript; MR participated in the design of the study and has been involved in revising critically the manuscript; LF has been involved in revising critically the manuscript; NN participated in the design of the study and has been involved in revising critically the manuscript; All authors read and approved the final manuscript.

\section{Acknowledgements}

- VLIR project/UCB for the material support in the achievement of all urine tests of this study:

- Department of Medical Biology of Cliniques Saint Luc/Brussels, for the calibration of serum creatinine;

- Department of Nephrology of Cliniques Saint Luc/Brussels, for financial support for some blood tests.

\section{Author details}

'Department of Medicine, Université Catholique de Bukavu, Bukavu, DR Congo. ${ }^{2}$ Nephrology Unit, Department of Medicine, Université de Kinshasa, Kinshasa, DR Congo. ${ }^{3}$ Department of Nephrology, Cliniques Universitaires Saint-Luc, Université catholique de Louvain, Brussels, Belgium. ${ }^{4}$ Clinical Chemistry Department, Cliniques Universitaires St Luc, Louvain Center for Toxicology And Applied Pharmacology, Université Catholique de Louvain, Brussels, Belgium. ${ }^{5}$ Department of Cardiovascular Sciences, KU Leuven, Leuven, Belgium. ${ }^{6}$ Postal address: 103 Cyangugu, Rwanda.

Received: 22 May 2014 Accepted: 28 August 2014

Published: 5 September 2014

\section{References}

1. Cailhol J, Nkurunziza B, Izzedine H, Nindagiye E, Munyana L, Baramperanye E, Nzorijana J, Sakubu D, Niyongabo T, Bouchaud O: Prevalence of chronic kidney disease among people living with HIV/AIDS in Burundi: a cross-sectional study. BMC Nephrol 2011, 2:40.

2. Emem CP, Arogundade F, Sanusi A, Adelusola K, Wokoma F, Akinsola A: Renal disease in HIV-seropositive patients in Nigeria: an assessment of prevalence, clinical features and risk factors. Nephrol Dial Transplant 2008, 23(2):741-746.

3. Taal MW, Brenner BM: Predicting initiation and progression of chronic kidney disease: developing renal risk scores. Kidney Int 2006, 70(10):1694-1705.

4. Jafar TH, Schmid CH, Landa M, Giatras I, Toto R, Remuzzi G, Maschio G, Brenner BM, Kamper A, Zucchelli P, Becker G, Himmelmann A, Bannister K, Landais P, Shahinfar S, de Jong PE, de Zeeuw D, Lau J, Levey AS: Angiotensin-converting enzyme inhibitors and progression of nondiabetic renal disease: a meta-analysis of patient-level data. Ann Intern Med 2001, 135(2):73-87.

5. Szczech LA, Gupta SK, Habash R, Guasch A, Kalayjian R, Appel R, Fields TA, Svetkey LP, Flanagan KH, Klotman PE, Winston JA: The clinical epidemiology and course of the spectrum of renal diseases associated with HIV infection. Kidney Int 2004, 66(3):1145-1152.

6. Wyatt CM, Morgello S, Katz-Malamed R, Wei C, Klotman ME, Klotman PE, D'Agati VD: The spectrum of kidney disease in patients with AIDS in the era of antiretroviral therapy. Kidney Int 2009, 75(4):428-434

7. Gupta SK, Eustace JA, Winston JA, Boydstun II, Ahuja TS, Rodriguez RA, Tashima KT, Roland M, Franceschini N, Palella FJ, Lennox JL, Klotman PE, Nachman SA, Hall SD, Szczech LA: Guidelines for the management of chronic kidney disease in HIV-infected patients: recommendations of the HIV Medicine Association of the Infectious Diseases Society of America. Clin Infect Dis 2005, 40(11):1559-1585.

8. Ginsberg JM, Chang BS, Matarese RA, Garella S: Use of single voided urine samples to estimate quantitative proteinuria. N Engl J Med 1983, 309(25):1543-1546.

9. Siedner MJ, Atta MG, Lucas GM, Perazella MA, Fine DM: Poor validity of urine dipstick as a screening tool for proteinuria in HIV-positive patients. J Acquir Immune Defic Syndr 2008, 47(2):261-263.

10. Glynn JR, Carael M, Auvert B, Kahindo M, Chege J, Musonda R, Kaona F, Buve A: Why do young women have a much higher prevalence of HIV than young men? A study in Kisumu, Kenya and Ndola, Zambia. AIDS 2001, 15(Suppl 4):S51-S60.

11. Morison L: The global epidemiology of HIV/AIDS. Br Med Bull 2001, 58:7-18.

12. Fabian J, Naicker S, Venter WD, Baker L, Naidoo S, Paget G, Wadee S: Urinary screening abnormalities in antiretroviral-naive HIV-infected outpatients and implications for management-a single-center study in South Africa. Ethn Dis 2009, 19(1 Suppl 1):S1-80-S1-85.

13. Jao J, Palmer D, Leus I, Tih P, Baweja M, Klotman M, Sperling R, Wyatt C: Prevalence and predictors of proteinuria in HIV-infected and uninfected pregnant women in Cameroon. Nephrol Dial Transplant 2011, 26(9):3051-3053.

14. Struik GM, den Exter RA, Munthali C, Chipeta D, Van Oosterhout JJ, Nouwen $J$, Allain TJ: The prevalence of renal impairment among adults with early HIV disease in Blantyre, Malawi. Int J STD AIDS 2011, 22(8):457-462.

15. Longo AL, Lepira FB, Sumaili EK, Makulo JR, Mukumbi H, Bukabau JB, Mokoli VM, Kayembe PK, Nseka NM: Prevalence of low estimated glomerular filtration rate, proteinuria, and associated risk factors among HIV-infected black patients using Cockroft-Gault and modification of diet in renal disease study equations. J Acquir Immune Defic Syndr 2011, 59(1):59-64.

16. Baekken M, Os I, Sandvik L, Oektedalen O: Microalbuminuria associated with indicators of inflammatory activity in an HIV-positive population. Nephrol Dial Transplant 2008, 23(10):3130-3137.

17. Szczech LA, Grunfeld C, Scherzer R, Canchola JA, van der Horst C, Sidney S, Wohl D, Shlipak MG: Microalbuminuria in HIV infection. AIDS 2007, 21(8):1003-1009.

18. Kimmel PL, Umana WO, Bosch JP: Abnormal urinary protein excretion in HIV-infected patients. Clin Nephrol 1993, 39(1):17-21.

19. Han TM, Naicker S, Ramdial PK, Assounga AG: A cross-sectional study of HIV-seropositive patients with varying degrees of proteinuria in South Africa. Kidney Int 2006, 69(12):2243-2250.

20. Hurlimann D, Weber R, Enseleit F, Luscher TF: HIV infection, antiretroviral therapy, and endothelium. Herz 2005, 30(6):472-480.

21. Zeller A, Sigle JP, Battegay E, Martina B: Value of a standard urinary dipstick test for detecting microalbuminuria in patients with newly diagnosed hypertension. Swiss Med Wkly 2005, 135(3-4):57-61.

22. Garcia C, Bordier L, Burnat P, Ceppa F, Dupuy O, Mayaudon H, Bauduceau B: Urinary dipsticks must not be used to detect diabetes-induced incipient nephropathy. Presse Med 2006, 35(7-8):1117-1121.

23. Giacomet V, Erba P, Di Nello F, Coletto S, Vigano A, Zuccotti G: Proteinuria in paediatric patients with human immunodeficiency virus infection. World J Clin Cases 2013, 1(1):13-18.

24. Kidney Disease: Improving Global Outcomes (KDIGO) CKD Work Group: KDIGO 2012 clinical practice guideline for the evaluation and management of chronic kidney disease. Kidney Inter 2013, 3:1-150.

25. Cavalcante MA, Coelho SN, Lacerda HR: Prevalence of persistent proteinuria in stable HIV/AIDS patients and its association with HIV nephropathy. Braz J Infect Dis 2007, 11(5):456-461.

doi:10.1186/1471-2369-15-146

Cite this article as: Masimango et al:: Prevalence of microalbuminuria and diagnostic value of dipstick proteinuria in outpatients from HIV clinics in Bukavu, the Democratic Republic of Congo. BMC Nephrology $201415: 146$ 